\title{
ISOTOPIC STUDIES OF PLASMA CHOLESTEROL OF ENDOGENOUS AND EXOGENOUS ORIGINS ${ }^{1}$
}

\author{
BY LEON HELLMAN, ROBERT S. ROSENFELD, MAXWELL L. EIDINOFF, \\ DAVID K. FUKUSHIMA, AND T. F. GALLAGHER \\ AND \\ CHUN-I WANG AND DAVID ADLERSBERG \\ (From the Divisions of Physics and Biophysics and Steroid Biochemistry and Metabolism, \\ Sloan-Kettering Institute for Cancer Research, and the Department of Medicine, \\ The Mount Sinai Hospital, New York, N. Y.)
}

(Submitted for publication June 16, 1954; accepted September 8, 1954)

This study was undertaken in order to compare the metabolic behavior of plasma cholesterol derived from the diet with that of cholesterol synthesized in vivo from acetate (1). Cholesterol labeled with either isotopic carbon or hydrogen was administered orally to human subjects and the incorporation into plasma cholesterol was followed over an extended period. In certain instances, both endogenous and exogenous cholesterol metabolism were studied simultaneously by the use of appropriately labeled acetate and cholesterol. These techniques were also applied to an examination of the behavior of plasma cholesterol in four patients with hypercholesterolemia.

\section{EXPERIMENTAL}

Subjects. The patients were hospitalized in the James Ewing Hospital unit of Memorial Center; all were in good clinical condition and a summary of pertinent data appears in Table I. Of the seven patients reported, three had normal plasma cholesterol levels and four had hypercholesterolemia of varied etiology.

Isotopic materials. The precise dosages of the labeled compounds are recorded in Table I. Cholesterol, either radiohydrogen (tritium or $\mathrm{H}^{2}$ ), heavy hydrogen (deuterium or $\left.\mathrm{H}^{2}\right)$, or radiocarbon $\left(\mathrm{C}^{\mathbf{4}}\right)$ labeled, was dissolved in sesame oil and fed in gelatin capsules. Sodium acetate labeled either with $\mathrm{C}^{16}$ or $\mathrm{H}^{2}$ was dissolved in $100 \mathrm{ml}$. of tap water and given orally. The quantity of radiation delivered by $\mathrm{C}^{14}$ to the patients as well as precautions to be observed in using this isotope in humans have already been described (1). Approximately 6 millicuries (mc.) of $\mathrm{H}^{2}$ are required to deliver the tolerance dose of radiation or 0.3 rep. per week, if this isotope were completely retained and equally distributed through

1 This investigation was carried out under contract AT(30-1)-910 with the United States Atomic Energy Commission and supported in part by research grants (C-440) from the National Cancer Institute and (H-564) from the National Heart Institute, of the National Institutes of Health, United States Public Health Service. the body. As the amount of $\mathbf{H}^{2}$ administered was considerably below this level, and since a large fraction of the dose was not retained, the quantity of radiation the patient receives from the isotope is far below tolerance levels.

The tritium-labeled sodium acetate with a specific activity of $0.55 \mathrm{mc}$. per millimole was made in this laboratory by exchange of malonic acid with tritium enriched water by the method of Halford and Anderson for preparation of deuterium-labeled acetate (2). Acetate-2-C was obtained from a commercial source and had a specific activity of $1 \mathrm{mc}$. per millimole. Cholesterol-4-C was prepared in this laboratory from cholestenone-4-C by the method of Belleau and Gallagher (3). The cholestenone-4-C $\mathrm{C}^{14}$ was obtained from the Oak Ridge National Laboratory, and had a specific activity of $2.3 \mathrm{mc}$. per millimole. Deuterium labeled cholesterol was prepared by catalytic exchange of cholesterol with heavy water in the manner described by Bloch and Rittenberg (4). Tritium-labeled cholesterol, with the isotope chiefly at positions $\mathrm{C}-14$ and $\mathrm{C}-15$, was made in this laboratory by the following procedure which has not been described previously.

A solution of one gram of $\Delta^{14}$-cholestene-3 $\beta$-ol acetate (5), $5 \mathrm{ml}$. (10 curies) of tritium acetic acid, and $30 \mathrm{ml}$. of anhydrous ether was reduced with $254 \mathrm{mg}$. of Adams' catalyst and hydrogen gas until the absorption ceased. The crude cholestanyl acetate was treated with a dilute solution of perbenzoic acid in benzene overnight at room temperature. Ten grams of non-isotopic cholestanyl acetate were added to the mixture and the diluted cholestane$3 \beta-01-14,15-t$ acetate was purified by chromatography and recrystallization. Saponification of the acetate followed by oxidation of cholestanol with sodium dichromate gave eight grams of cholestane-3-one-14,15-t which was then converted to four grams of $\Delta^{4}$-cholestene-3-one (6). Sodium borohydride reduction (3) of the enol acetate prepared from the unsaturated ketone afforded cholesterol$14,15-t$, m.p. 149 to $149.5^{\circ}$.

Blood samples of thirty to forty $\mathrm{ml}$. were collected at frequent intervals in either oxalated or heparinized tubes for the isolation of free and ester cholesterol as the digitonide by the procedure described elsewhere (7). In those cases where cholesterol-4-C $C^{14}$ was administered, collections of expired carbon dioxide were made in order to determine whether the steroid nucleus was broken 
TABLE I

Clinical data on patients

\begin{tabular}{|c|c|c|c|c|c|c|c|c|c|}
\hline \multirow[b]{2}{*}{ Patient } & \multirow[b]{2}{*}{ Sex } & \multirow[b]{2}{*}{ Age } & \multirow{2}{*}{$\begin{array}{l}\text { Wet. } \\
\text { (lbs.) }\end{array}$} & \multirow[b]{2}{*}{ Diagnoois } & \multicolumn{2}{|c|}{$\begin{array}{c}\text { Plasma } \\
\text { cholesterral } \\
\text { s. } / 1000 \mathrm{ml} .\end{array}$} & \multicolumn{3}{|c|}{ Labeled materials } \\
\hline & & & & & Total & $\overline{\text { Free }}$ & Compound & Weight & Activity \\
\hline$\overline{\mathrm{CHC}-1}$ & $\mathbf{M}$ & 58 & 130 & $\begin{array}{l}\text { Pancreas } \\
\text { carcinoma }\end{array}$ & 150 & 50 & $\begin{array}{l}\text { Cholesterol-4-C'4 } \\
\text { Acetate-2- } \mathrm{H}^{3}\end{array}$ & $\begin{array}{l}15.4 \mathrm{mg} . \\
98 \mathrm{mg} .\end{array}$ & $\begin{aligned} & 91 \mu c . \\
& 700 \mu c .\end{aligned}$ \\
\hline CHC-2 & $\mathbf{F}$ & 30 & 115 & $\begin{array}{l}\text { Functioning } \\
\text { adrenal } \\
\text { cortical } \\
\text { carcinoma }\end{array}$ & 235 & 62 & $\begin{array}{l}\text { Cholesterol-4-Cis } \\
\text { Acetate-2- } \mathrm{H}^{3}\end{array}$ & $\begin{array}{r}10.1 \mathrm{mg} . \\
67 \mathrm{mg} .\end{array}$ & $\begin{array}{r}60 \mu c . \\
480 \mu c .\end{array}$ \\
\hline CHC-3 & $\mathbf{F}$ & 34 & 131 & $\begin{array}{l}\text { Cushing's } \\
\text { syndrome }\end{array}$ & 200 & 66 & 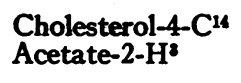 & $\begin{array}{l}9.5 \mathrm{mg} . \\
67 \mathrm{mg} .\end{array}$ & $\begin{array}{r}56 \mu c . \\
480 \mu c .\end{array}$ \\
\hline CHC-4 & $\mathbf{F}$ & 56 & 115 & $\begin{array}{l}\text { Hypercholes- } \\
\text { terolemia } \\
\text { Xanthoma } \\
\text { tendinosum }\end{array}$ & 410 & 106 & Cholesterol-4-Cic & $20.6 \mathrm{mg}$. & $122 \mu c$. \\
\hline CHC-5 & $\mathbf{F}$ & 41 & 116 & $\begin{array}{l}\text { Hypercholes- } \\
\text { terolemia } \\
\text { Xanthoma } \\
\text { tendinosum }\end{array}$ & 408 & 122 & $\begin{array}{l}\text { Cholesterol-4-Cid } \\
\text { Cholesterol-H² }\end{array}$ & $\begin{array}{c}10.7 \mathrm{mg} . \\
1.0 \mathrm{~g} .\end{array}$ & $\begin{array}{r}63 \mu \mathrm{c} . \\
11.87 \mathrm{AD}^{*}\end{array}$ \\
\hline CHC-6 & $\mathbf{M}$ & 43 & 160 & $\begin{array}{l}\text { Nephrotic } \\
\text { syndrome }\end{array}$ & 420 & 100 & Cholesterol-4-Cis & $10.7 \mathrm{mg}$. & $63 \mu c$. \\
\hline CHT-1 & $\mathbf{F}$ & 49 & 115 & $\begin{array}{l}\text { Hypercholes- } \\
\text { terolemia } \\
\text { Xanthoma } \\
\text { tuberosum }\end{array}$ & 812 & 301 & $\begin{array}{l}\text { Acetate-2-C14 } \\
\text { Cholesterol-H' }\end{array}$ & $\begin{array}{l}16 \mathrm{mg} . \\
7.5 \mathrm{mg} .\end{array}$ & $\begin{array}{l}200 \mu c . \\
113 \mu c .\end{array}$ \\
\hline
\end{tabular}

* $\mathrm{AD}=$ atom per cent excess deuterium.

down to compounds that might be oxidized to carbon dioxide. Urine and feces were obtained for variable periods of time to measure the excretion of the administered radioactivity through these routes, as well as for the isolation of steroid metabolites. These latter data will be presented in detail in a separate communication, although preliminary results have been reported $(8,9)$.

Radioactivity measurements. The methods used for the measurement of radioactivity of cholesterol digitonide samples containing only $\mathrm{C}^{2}$ have been previously reported (1). The tritium analyses were carried out on cholesterol digitonide by proportional counting in the gas phase by the method described by Eidinoff (10).

In those experiments in which acetate and cholesterol were given simultaneously, the cholesterol digitonide isolated from the plasma contained both isotopes. The digitonide was burned in a combustion apparatus similar to that described by Glascock (11) and simultaneous collection of both water and carbon dioxide was made. The water was converted to hydrogen and counted in the gas phase in the proportional region (10). Radiocarbon activity was assayed as carbon dioxide admixed with carbon disulfide in the Geiger-Müller region (12).

The carbon-14 content of certain solid samples containing both carbon-14 and tritium was determined in windowless flow gas counters with an aluminum foil ( $0.13 \mathrm{mg}$. per $\mathrm{cm}^{2}$ ) placed over the planchet to absorb the tritium beta particles. This foil removed approximately 90 per cent of the tritium radiation, but permitted about 80 per cent of the carbon beta particles to pass. An accurate estimation of the tritium content of a sample could not be made by this procedure, but since a constant portion of the carbon radiation passed through the foil, it was adequate for the measurement of the carbon-14 content of a sample containing both isotopes.2

$$
\begin{aligned}
C & =C_{0} \frac{C_{B} / C_{0}-f_{t r}}{f_{0}-f_{t r}} \\
C & =\text { true carbon count } \\
C_{0} & =\text { net count unshielded } \\
C_{B} & =\text { net count shielded } \\
f_{b} & =\text { fraction of } C^{4} \text { transmitted through shield } \\
f_{t r} & =\text { fraction of } H^{3} \text { transmitted through shield }
\end{aligned}
$$

$f_{0}$ and $f_{t r}$ were determined once each week for each aluminum shield. The $f_{o}$ was measured by counting a shielded sample containing $\mathrm{C}^{14}$ only, while $f_{\text {tr }}$ was determined in the same manner with a sample containing only $\mathrm{H}^{\mathbf{3}}$.

The $\mathrm{C}^{24}$ content of urine was measured with $0.2 \mathrm{ml}$. of urine dried on a planchet of $4.9 \mathrm{~cm}^{2}$ area containing a piece of lens paper of the same dimensions. The lens

${ }^{2}$ Calculation for determining radiocarbon by solid counting in the presence of tritium: 
HELLMAN ET AL.

TABLE II

Radioactivity of plasma chabesterol in subjects with normal cholester ol levels

\begin{tabular}{|c|c|c|c|c|c|c|c|c|c|c|c|c|}
\hline \multicolumn{5}{|c|}{ CHC-1 } & \multicolumn{5}{|c|}{ CHC-2 } & \multirow{2}{*}{\multicolumn{3}{|c|}{$\frac{\text { CHC-3 }}{\text { From cholesterol-4-Cu }}$}} \\
\hline \multicolumn{3}{|c|}{ From cholesteral-1-C14 } & \multicolumn{2}{|c|}{ From acetate-2-H } & \multicolumn{3}{|c|}{ From cholesterol-4-C14 } & \multicolumn{2}{|c|}{ From acetate-2-Hs } & & & \\
\hline Time* & Freet & Eetert & Freet & Estert & Time* & Freet & Estert & Freet & Estert & Time* & Freet & Estert \\
\hline $\begin{array}{l}0.125 \\
0.35 \\
0.73 \\
1.2 \\
1.75 \\
2.2 \\
2.75 \\
3.2 \\
3.75\end{array}$ & $\begin{array}{l}22.0 \\
61.0 \\
81.2 \\
135.5 \\
125 \\
144 \\
137 \\
129.5 \\
129.0\end{array}$ & $\begin{array}{c}3.18 \\
43.0 \\
85.4 \\
137.5 \\
151.5 \\
174.5 \\
179.5 \\
167 \\
173\end{array}$ & $\begin{array}{c}26.9 \\
16.4 \\
12.5 \\
11.8 \\
9.16 \\
9.21 \\
9.21 \\
7.80 \\
6.48\end{array}$ & $\begin{array}{l}2.95 \\
6.67 \\
7.04 \\
6.75 \\
8.44 \\
7.84 \\
5.57 \\
7.65 \\
8.05\end{array}$ & $\begin{array}{l}0.167 \\
0.39 \\
0.94 \\
1.27 \\
2 \\
3 \\
4 \\
5 \\
7 \\
10\end{array}$ & $\begin{array}{r}118 \\
722 \\
1,500 \\
1,620 \\
1,420 \\
1,180 \\
941 \\
840 \\
643 \\
535\end{array}$ & $\begin{array}{c}93.5 \\
610 \\
1,030 \\
1,110 \\
1,280 \\
1,280 \\
1,240 \\
1,120 \\
865 \\
711\end{array}$ & $\begin{array}{r}27.8 \\
18.7 \\
8.71 \\
8.69 \\
10.92 \\
8.86 \\
6.49 \\
6.17 \\
\\
4.98\end{array}$ & $\begin{array}{l}5.32 \\
5.37 \\
7.38 \\
7.72 \\
9.65 \\
9.23 \\
8.44 \\
8.15 \\
6.55 \\
3.96\end{array}$ & $\begin{array}{l}0.184 \\
0.417 \\
0.805 \\
1.11 \\
1.84 \\
2.18 \\
2.83 \\
4.0 \\
6 \\
7 \\
8 \\
11 \\
13 \\
14\end{array}$ & $\begin{array}{l}134 \\
446 \\
681 \\
622 \\
584 \\
554 \\
476 \\
452 \\
344 \\
286 \\
217 \\
148 \\
139 \\
134\end{array}$ & $\begin{array}{l}117.5 \\
422 \\
414 \\
562 \\
601 \\
664 \\
612 \\
575 \\
488 \\
423 \\
368 \\
240 \\
198 \\
188\end{array}$ \\
\hline
\end{tabular}

* Elapsed time in days after administration of labeled material.

$\times 10^{3}$ DPM per $\mathrm{mM}$ cholesterol.

$\ddagger \times 10^{3} \mathrm{DPM}$ per $\mathrm{mM} \mathrm{H}_{2}$.

TABLE III

Radioactioity of plasma cholesterol after administration of cholesterol-4-C to hypercholesterolemic subjects

\begin{tabular}{|c|c|c|c|c|c|c|c|c|}
\hline \multicolumn{3}{|c|}{$\mathrm{CHC}_{-4}$} & \multicolumn{3}{|c|}{ CHC-5 } & \multicolumn{3}{|c|}{ CHC-6 } \\
\hline Time & Freet & Estert & Time* & Freet & Estert & Time* & Freet & Estert \\
\hline $\begin{array}{c}0.04 \\
0.62 \\
1.1 \\
1.6 \\
2 \\
2.6 \\
3.1 \\
3.6 \\
5.6 \\
6.6 \\
7.6 \\
8.6 \\
9.6 \\
10.6 \\
11.6 \\
12.6 \\
14.6 \\
16.6 \\
20.6 \\
21.6 \\
23.6 \\
26.6 \\
29.6 \\
33.6 \\
36.6 \\
140.0\end{array}$ & $\begin{array}{c}98.5 \\
1,112 \\
1,760 \\
1,750 \\
1,575 \\
1,480 \\
1,420 \\
1,335 \\
974 \\
982 \\
830 \\
741 \\
728 \\
660 \\
587 \\
552 \\
556 \\
441 \\
413 \\
396 \\
363 \\
324 \\
302 \\
236 \\
197 \\
59.0\end{array}$ & $\begin{array}{l}- \\
= \\
= \\
= \\
= \\
= \\
- \\
1,084 \\
988 \\
864 \\
791 \\
718 \\
718 \\
597 \\
484 \\
457 \\
397 \\
381 \\
315 \\
326 \\
308 \\
82.3\end{array}$ & $\begin{array}{l}0.167 \\
0.375 \\
0.845 \\
1.06 \\
1.44 \\
1.44 \\
\text { ratioł } \\
1.87 \\
2.87 \\
2.87 \\
\text { ratioł } \\
3.9 \\
5 \\
6 \\
7 \\
8 \\
10 \\
13 \\
13 \\
\text { ratioł } \\
15 \\
17 \\
20 \\
22 \\
24 \\
28 \\
35 \\
43 \\
52 \\
66 \\
76 \\
92 \\
105 \\
144 \\
167\end{array}$ & $\begin{array}{c}24.3 \\
126.7 \\
215 \\
246 \\
255 \\
0.0608 \\
0.24 \ddagger \\
275 \\
210 \\
0.0488 \\
0.23 \ddagger \\
210 \\
167 \\
162 \\
121.5 \\
116 \\
111 \\
93.2 \\
0.0228 \\
0.24 \ddagger \\
71.5 \\
62.8 \\
58.6 \\
57.6 \\
60.3 \\
46.7 \\
49.7 \\
42.3 \\
39.0 \\
27.8 \\
27.6 \\
19.7 \\
17.0 \\
12.8\end{array}$ & $\begin{array}{c}11.5 \\
64.3 \\
124.7 \\
204 \\
204 \\
0.0458 \\
0.22 \ddagger \\
214 \\
255 \\
0.057 \S \\
0.22 \ddagger \\
256 \\
207 \\
197 \\
185 \\
172 \\
152 \\
111 \\
0.026 \S \\
0.23 \ddagger \\
106 \\
94.4 \\
82.6 \\
76.4 \\
72.2 \\
62.0 \\
54.0 \\
46.3 \\
38.9 \\
33.2 \\
31.2 \\
20.5 \\
14.3 \\
13.9\end{array}$ & $\begin{array}{c}0.33 \\
1 \\
2 \\
3 \\
5 \\
7 \\
10 \\
14 \\
17 \\
22 \\
27 \\
34 \\
41 \\
48 \\
55 \\
62 \\
69 \\
76 \\
83 \\
97 \\
110 \\
124 \\
138\end{array}$ & $\begin{array}{c}320 \\
338 \\
417 \\
425 \\
357 \\
297 \\
239 \\
179 \\
154 \\
104 \\
101 \\
69.0 \\
59.4 \\
56.6 \\
43.3 \\
33.8 \\
32.3 \\
33.6 \\
39.2 \\
24.0 \\
20.7 \\
17.5 \\
12.5\end{array}$ & $\begin{array}{c}408 \\
622 \\
604 \\
437 \\
404 \\
338 \\
266 \\
215 \\
169 \\
117.5 \\
93.7 \\
77.3 \\
68.7 \\
74.0 \\
55.7 \\
44.8 \\
36.4 \\
37.2 \\
25.4 \\
23.9 \\
- \\
-\end{array}$ \\
\hline
\end{tabular}

* Elapsed time in days after administration of labeled material.

$\times 10^{3}$ DPM per mM cholesterol.

Ratio of deuterium content $\times 10^{\circ}$ to radiocarbon content.

Atom per cent excess deuterium in cholesterol (AD). 
paper facilitated even distribution over the surface of the planchet to give plates of uniform thickness. Feces were extracted three times in a Waring Blendor with three volumes of acetone. A portion of the acetone extract was plated on lens paper in the manner described for urine.

The various counting procedures were intercalibrated with a reference sodium carbonate- $C^{\mathbf{1 4}}$ standard obtained from the National Bureau of Standards. The radioactivity of cholesterol samples containing carbon-14 is expressed in units of "disintegrations per minute per millimole" (DPM per $\mathrm{mM}$ ). The tritium radioactivity data are expressed in units of "disintegrations per minute per millimole of hydrogen" (DPM per $\mathbf{m M ~} \mathbf{H}_{2}$ ).

\section{RESULTS}

Three patients, CHC-1, CHC-2, CHC-3, with normal plasma cholesterol levels each received from 50 to 90 microcuries ( $\mu$ c.) of cholesterol-4$\mathrm{C}^{14}$ and from 500 to $700 \mu \mathrm{c}$. of tritium-labeled acetate. Three other patients, CHC-4, CHC-5, CHC-6, with elevated plasma cholesterol levels, received from 60 to $120 \mu \mathrm{c}$. of cholesterol-4-C ${ }^{14}$; $1.016 \mathrm{gm}$. of cholesterol containing 11.87 atoms per cent excess deuterium was given to subject CHC-5 along with the $\mathrm{C}^{14}$ cholesterol. An additional patient with hypercholesterolemia, CHT-1, received $113.2 \mu \mathrm{c}$. of tritium labeled cholesterol and $200 \mu \mathrm{c}$. of acetate-2-C $\mathrm{C}^{\mathbf{4}}$.

The specific activities of free and ester cholesterol isolated from patients $\mathrm{CHC}-1, \mathrm{CHC}-2$, CHC-3 are listed in Table II. Table III contains the specific activity data from subjects $\mathrm{CHC}-4$, CHC-5, CHC-6, while the results obtained in CHT-1 are listed in Table IV.

The data obtained for four and a half days following the simultaneous administration of acetate$\mathrm{H}^{3}$ and cholesterol-4- $\mathrm{C}^{14}$ to subject $\mathrm{CHC}-1$ are plotted in Figure 1. As shown on the lower right portion of this figure, the specific activity of free cholesterol synthesized in vivo from acetate is at a maximum with the earliest sample and then declines rather rapidly. The ester cholesterol derived from acetate is at a minimum value with the first sample and then gradually rises until it intersects the free curve at approximately three days, after which the specific activity of the ester cholesterol exceeds that of the free. For comparison with these tritium data, specific activity curves previously reported from a patient who received
TABLE IV

Radioactivity of plasma cholesterol in a hypercholesterolemic subject given acetate-2-C't and cholesterol- $H^{3}$

\begin{tabular}{|c|c|c|c|c|}
\hline \multicolumn{5}{|c|}{ CHT-1 } \\
\hline \multirow[b]{2}{*}{ Time* } & \multicolumn{2}{|c|}{ From acetate-2-C14 } & \multicolumn{2}{|c|}{ From cholesterol-H² } \\
\hline & Freet & Estert & Freet & Estert \\
\hline $\begin{array}{l}0.125 \\
0.33 \\
0.80 \\
1.26 \\
1.73 \\
2.73 \\
3.73 \\
4.73 \\
6.73 \\
8.73 \\
10.73 \\
13.73 \\
17.73 \\
22 \\
25\end{array}$ & $\begin{array}{l}568 \\
535 \\
450 \\
372 \\
365 \\
263 \\
222 \\
180 \\
166 \\
154 \\
118 \\
108 \\
88.4 \\
82.4 \\
61.4\end{array}$ & $\begin{array}{r}18.1 \\
53.7 \\
85.7 \\
122.8 \\
126.5 \\
154.2 \\
155.0 \\
172.0 \\
151.8 \\
158.2 \\
129.5 \\
117.5 \\
102.0 \\
86.0 \\
85.5\end{array}$ & $\begin{array}{r}3.3 \\
25.3 \\
41.7 \\
41.1 \\
50.3 \\
49.8 \\
48.6 \\
42.8 \\
41.5 \\
36.4 \\
29.2 \\
28.2 \\
25.1 \\
21.0 \\
18.6\end{array}$ & $\begin{array}{l}2.79 \\
27.3 \\
43.0 \\
67.8 \\
68.8 \\
78.6 \\
66.0 \\
63.6 \\
54.2 \\
46.2 \\
35.3 \\
31.9 \\
28.6 \\
25.8 \\
22.4\end{array}$ \\
\hline $\begin{array}{r}29 \\
32 \\
36 \\
39 \\
43 \\
49 \\
61 \\
86 \\
115\end{array}$ & $\begin{array}{l}\overline{53.6} \\
52.8 \\
50.0 \\
44.8 \\
43.3 \\
36.6 \\
28.9 \\
20.4\end{array}$ & $\begin{array}{l}\overline{68.5} \\
62.6 \\
55.0 \\
55.7 \\
48.4 \\
37.0 \\
33.8 \\
23.3\end{array}$ & $\begin{array}{l}\overline{15.8} \\
14.8 \\
13.7 \\
12.7 \\
11.95 \\
\overline{8.15} \\
6.62\end{array}$ & $\begin{array}{l}\overline{18.1} \\
16.2 \\
15.8 \\
15.6 \\
13.9 \\
11.2 \\
11.85 \\
6.12\end{array}$ \\
\hline
\end{tabular}

* Elapsed time in days after administration of labeled material.

$\dagger \times 10^{3}$ DPM per $\mathrm{mM}$ cholesterol.

$\neq \times 10^{3}$ DPM per mM $\mathrm{H}_{2}$.

C14-labeled acetate (1) are shown in the upper right portion of Figure 1. The behavior of cholesterol synthesized from acetate is similar whether the acetate is labeled with either tritium or $\mathrm{C}^{14}$, and these data and others to be presented demonstrate the interchangeable use of these two isotopes for the study of the conversion of acetate to cholesterol.

The activity of plasma free cholesterol originating in the diet is at a minimum value with the 3-hour sample, as illustrated on the left portion of Figure 1. The specific activity then rises to a peak at about 1.5 to 2 days and afterwards declines. The radioactivity of the "exogenous" plasma ester cholesterol is also at a minimum with the first sample, rises less rapidly than that of the free sterol, and reaches a peak value at about 2.5 days, having intersected the free curve at about 1 day. After this crossover point, the ester specific activity is greater than that of the free for the duration of the period of observation.

Figure 2 compares the incorporation of dietary 


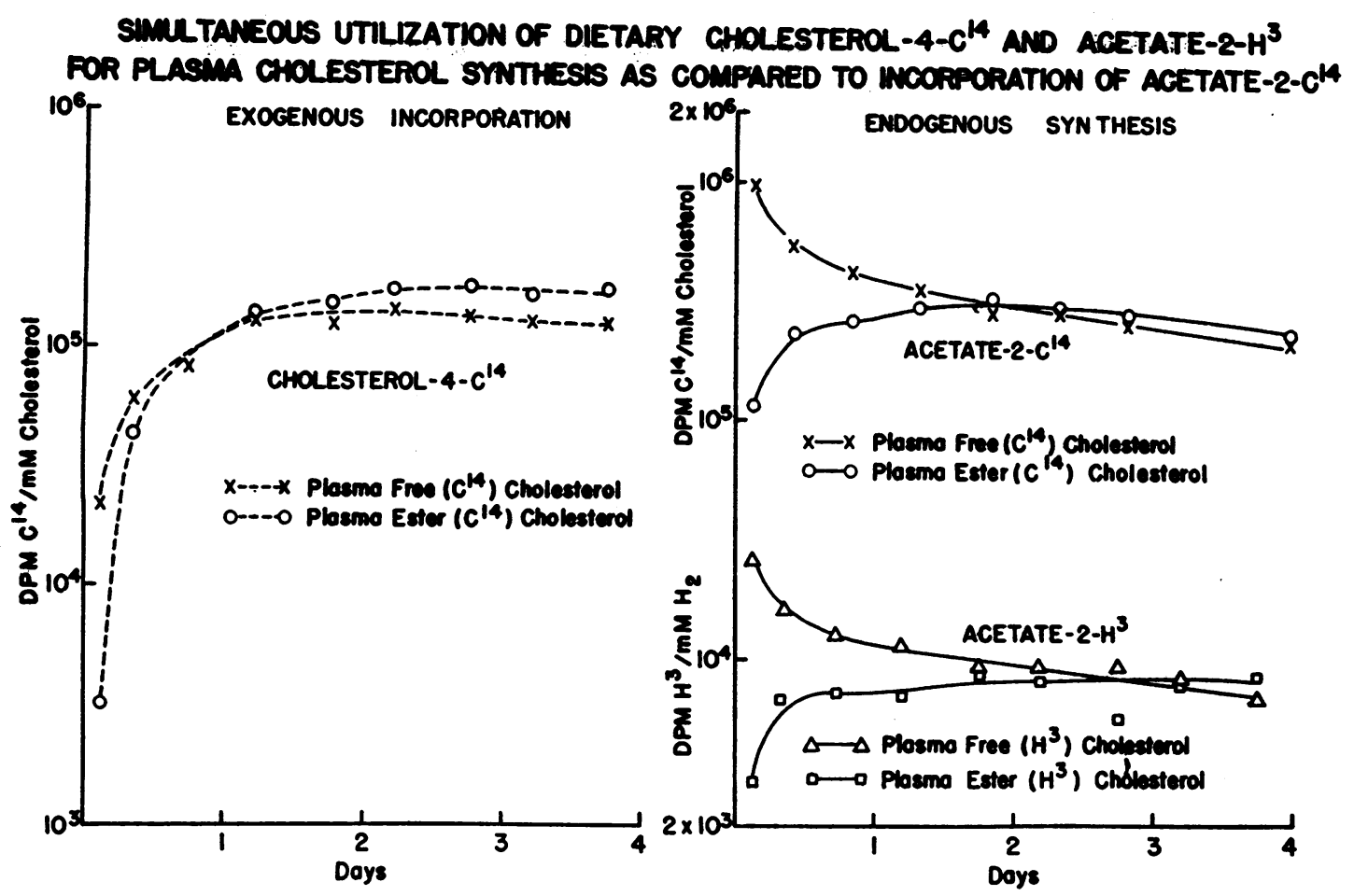

Fig. 1. The Smultaneous Utilization of Ingested Cholestrolo-4-C ${ }^{34}$ and Acetate-2-t for Plasma Cholesterol Synthesis as Compared with the Incorporation of Acetate-2-C

cholesterol-4-C $C^{14}$ into plasma cholesterol of a subject with a normal cholesterol level (CHC-2) with a patient who had hypercholesterolemia accompanying the xanthoma tendinosum syndrome (CHC-5). It can be seen that the mode of rise of free and ester cholesterol, the points of intersection, and the subsequent rate of decline over a ten-day period, are virtually indistinguishable. The specific activity of the plasma cholesterol in the normocholesterolemic patient is higher; however, this difference may be related to individual variation in the quantity of labeled cholesterol that had been absorbed. The dilution of the administered labeled sterol by the larger plasma cholesterol pool in the hypercholesterolemic might also explain the lower specific activity.

In Figures 3 and 4, results obtained over a longer period are presented for comparison of the rates of decline of endogenously and exogenously derived cholesterol. The plasma free cholesterol specific activities measured after the administration of labeled cholesterol to the hypercholesterolemic subject, CHC-4, are plotted in Figure 3 together with the specific activities of plasma free cholesterol of a normocholesterolemic subject who received labeled acetate. The acetate data have been previously reported (1). With the exception of the early differences in the behavior of endogenously or exogenously derived plasma cholesterol already described above, it will be noted that the radioactivity of free cholesterol whether absorbed from the diet or made in vivo, declines at a similar rate in these two patients during the 30-day period of observation. In Figure 4, the equivalent data for ester cholesterol in the hypercholesterolemic subject $\mathrm{CHC}-5$ and the typical acetate subject are shown and the similar rates of decline of sterol radioactivity in these dissimilar patients are again apparent.

Subject CHT-1 who had hypercholesterolemia associated with the xanthoma tuberosum syndrome received cholesterol- $\mathrm{H}^{8}$ and acetate-2-C $\mathrm{C}^{14}$ simultaneously. This patient was studied for six months and Figure 5 is a comparison of the behavior of cholesterol arising from these two sources for the first 43 days. The findings in this patient differ in two respects from those obtained in normocholesterolemic subjects and in 


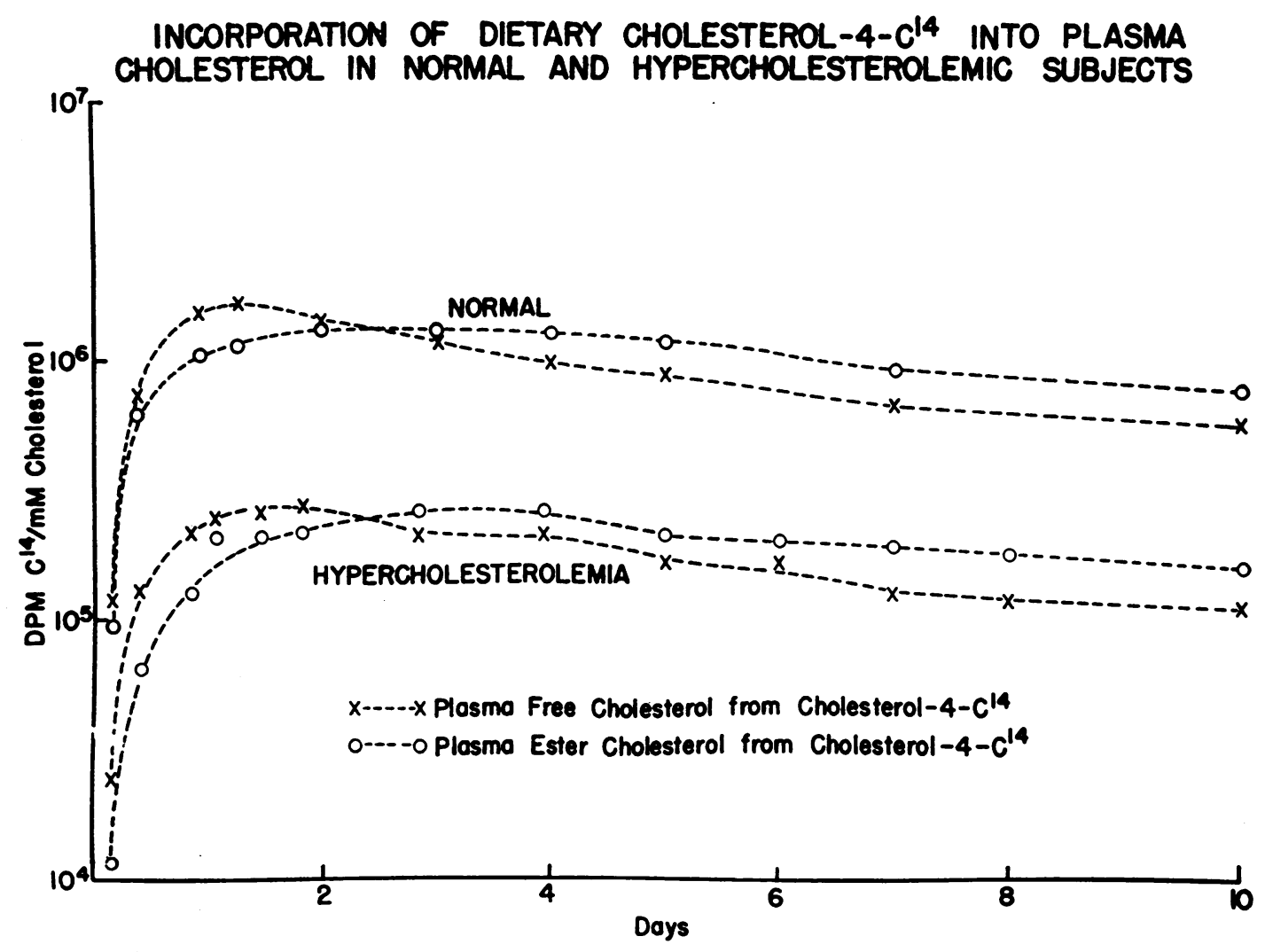

Fig. 2. The Ixcorporation of Ingested Cholesterol-4-C ${ }^{4}$ into Plasma Cholesterol in Subjects with Normal Cholesterol Levels and in Hypercholesterolemia

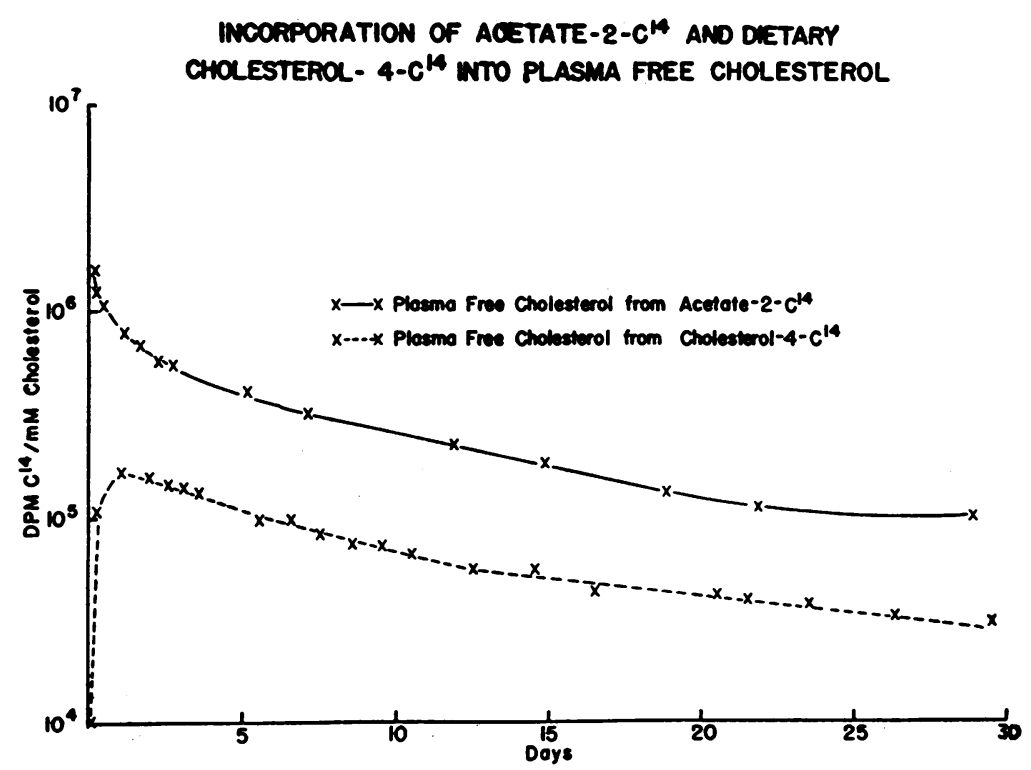

Fig. 3. The Incorporation of Acetatr-2-C and Ingested Cholesterol4-Ca into Plasma Frege Cholestrerol 


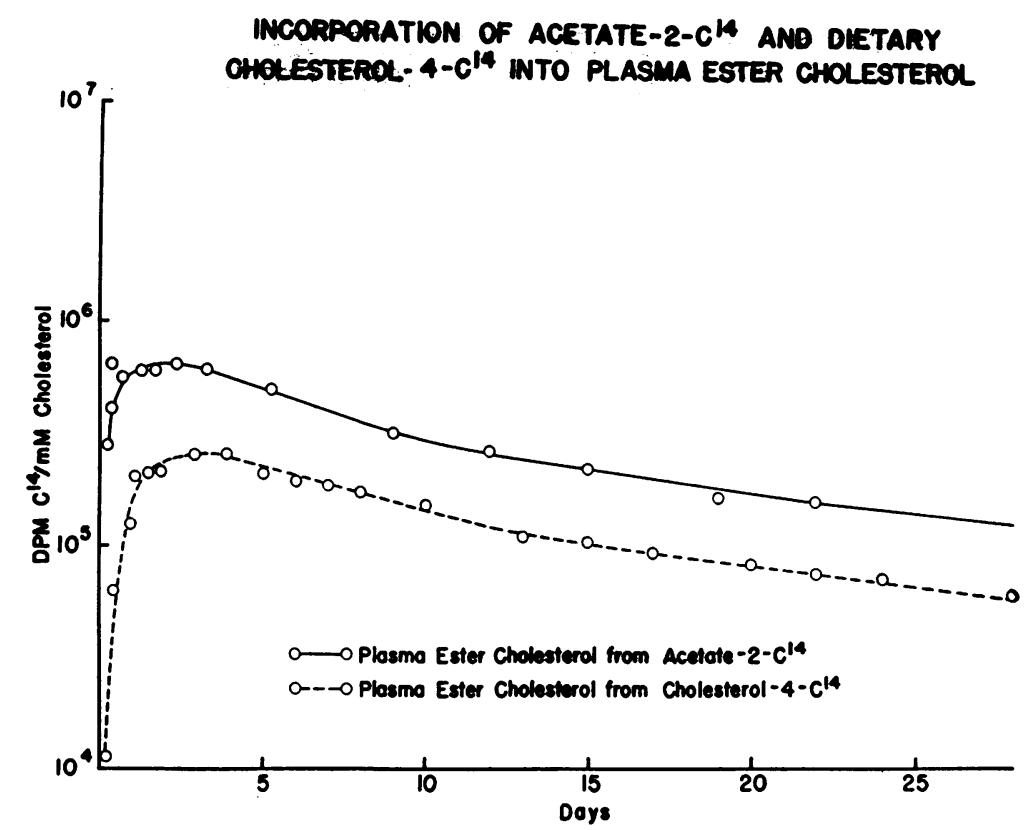

Fig. 4. The Incorporation of Acetate-2-C ${ }^{n}$ and Ingested Cholestrerol4-C ${ }^{14}$ into Plasma Ester Cholesterol

hypercholesterolemic subjects with the xanthoma tendinosum syndrome. Free cholesterol synthesized from acetate, although at a peak value with the initial sample, declines more slowly during the first few days of observation, so that the rising specific activity curve of ester cholesterol does not intersect the free curve until about the sixth day. In all patients previously studied with acetate, this point of intersection occurred at two to three days (1). Plasma cholesterol derived from the diet, differs in that the ester cholesterol specific activities are initially at a higher level, rise

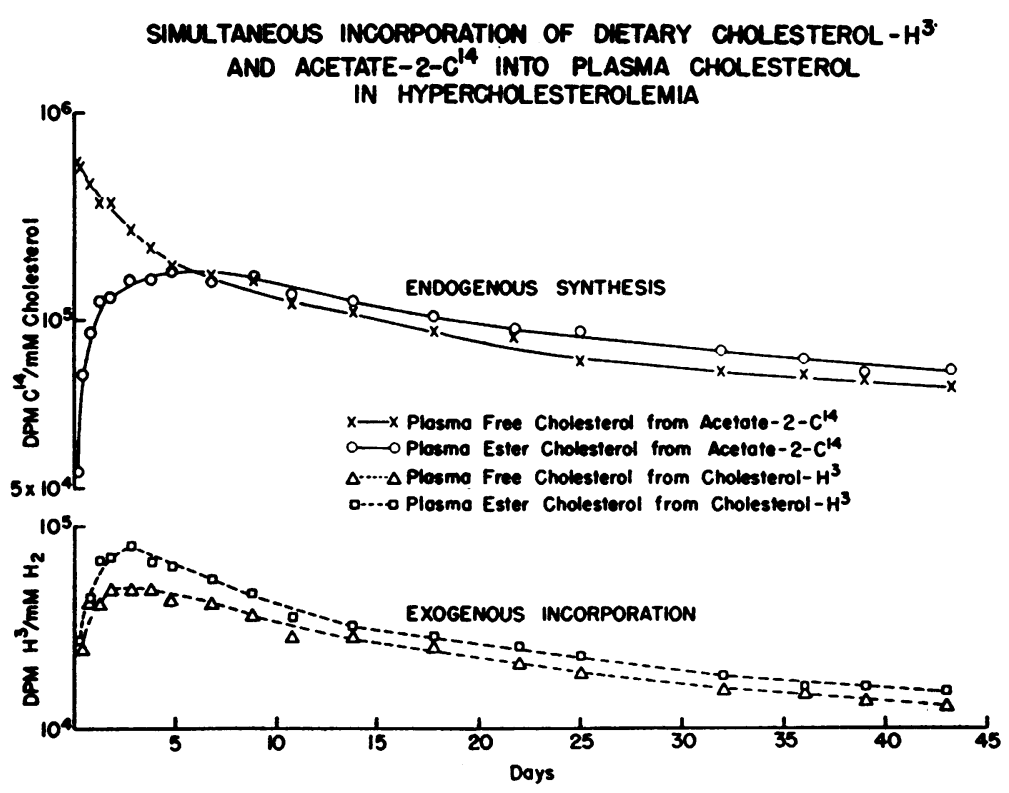

Fig. 5. Smultameous Incorporation of Ingrsted Chourstinol-t amd Acetate-2-Ch into Prasya Ceousterod ny Hypercholesterolemia 


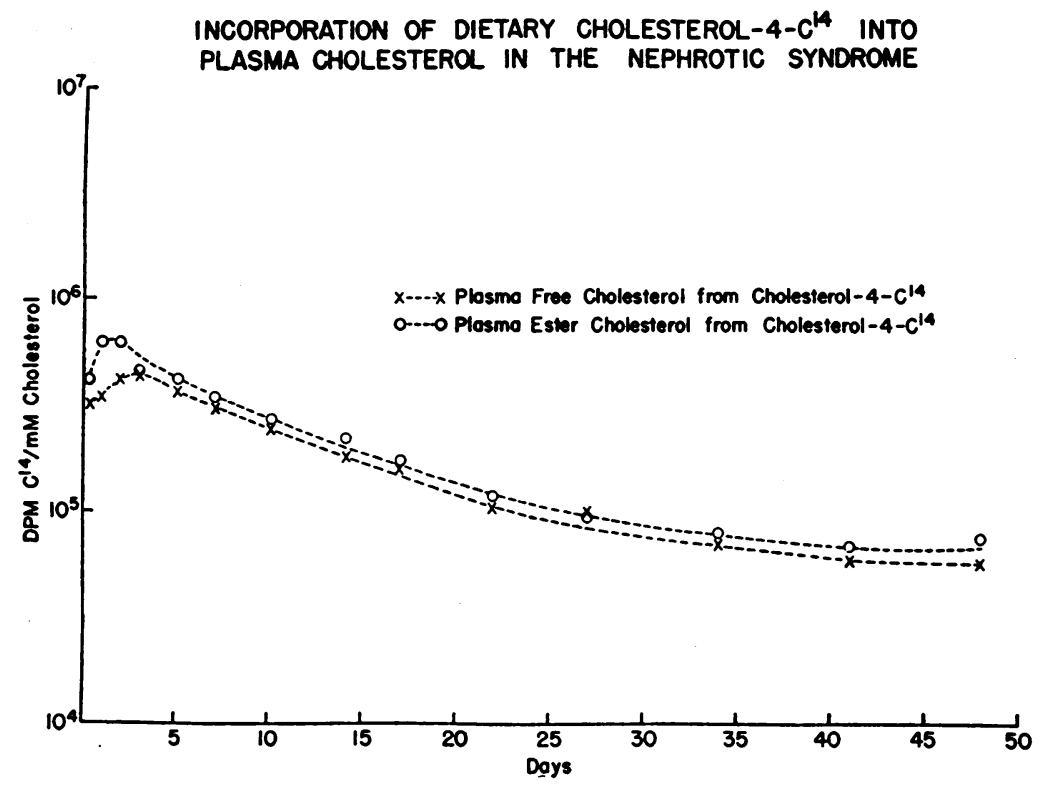

Fig. 6. Incorporation of Ingested Cholesterol-4-C ${ }^{14}$ into Plasma Cholesterol in the Nephrotic Syndrome

more rapidly, and exceed those of the free throughout the experiment. Since the free cholesterol specific activities are always below the ester values, the two specific activity curves do not intersect. The latter parts of the curves in Figure 5 show parallel rates of decline of cholesterol radioactivity similar to those observed in other patients with hypercholesterolemia and in patients with normal plasma cholesterol levels (Figures 3 and 4). These data derived after the simultaneous administration of labeled acetate and cholesterol show that either labeled compound yields identical results when used for the study of long term aspects of the behavior of plasma cholesterol.

Cholesterol-4-C ${ }^{14}$ was also given to a patient, CHC-6, who had hypercholesterolemia accompanying the nephrotic syndrome; the radioactivity of the plasma cholesterol is shown in Figure 6. Its behavior in this patient is similar to that observed in the subject with xanthoma tuberosum CHT-1.

An analysis of the specific activity curves in terms of component rate processes is presented in Table $\mathrm{V}$ and the similarities mentioned above for the decline of cholesterol radioactivity during the latter part of the experiments may be observed.

The radioactivity excreted in urine and feces in patients who received $\mathrm{C}^{14}$ cholesterol, as well as the levels of activity obtained in the blood, are recorded in Table VI. The recovery of administered radioactivity in feces by the fourth day varied from 14 to 48 per cent. A much smaller proportion, from 0.35 to 1.76 per cent, of the administered material was excreted in the urine during the same time interval. In the subjects whose plasma cholesterol specific activity curves exhibited a crossover of the free and ester cholesterol, 4 to 14 per cent of the ingested $\mathrm{C}^{14}$ sterol was present in circulating cholesterol at the peak radioactivity of plasma free cholesterol. In CHT-1 and CHC-6, where no crossover occurred, 27 and 12 per cent,

TABLE V

Component rates of decay curve of plasma cholesterol derived from labeled dietary cholesterol

\begin{tabular}{lcc}
\hline & \multicolumn{2}{c}{ Decay rates } \\
\cline { 2 - 3 } Subject & $\mathrm{a}$ & $\mathrm{b}$ \\
t\} & 22 & 3.0 \\
\hline CHC-4 & 22 & 2.5 \\
CHC-5 & 20 & 4.0 \\
CHC-6 & 19 & 1.9 \\
CHT-1 & 17 & 1.4 \\
CHT-1* & 23.0 & 2.3 \\
AC-3† & &
\end{tabular}

* Components of curves derived from acetate-2-C" given simultaneously with cholesterol- ${ }^{3}$ to subject $\mathrm{CHT}-1$.

+ Components of curve derived from acetate-2-C $C^{14}$ as previously reported (1). 
TABLE VI

Amount of labeled cholesterol found in plasma as compared with the fraction excreted in urine and feces

\begin{tabular}{|c|c|c|c|c|}
\hline \multirow[b]{2}{*}{ Subject } & \multirow{2}{*}{$\frac{\text { Intersection }}{\text { Days }}$} & \multirow{2}{*}{$\frac{\text { Total dose }}{\text { In plasma* }}$} & \multicolumn{2}{|c|}{ Four-day excretion } \\
\hline & & & Urine & Feces \\
\hline $\begin{array}{l}\text { CHC-2 } \\
\text { CHC-3 } \\
\text { CHC-4 } \\
\text { CHC-5 } \\
\text { CHC-6 } \\
\text { CHT-1 }\end{array}$ & $\begin{array}{c}2.2 \\
1.9 \\
t \\
2.9 \\
t \\
t\end{array}$ & $\begin{array}{r}\% \\
14 \\
7 \\
12 \\
4 \\
12 \\
27\end{array}$ & $\begin{array}{l}\% \\
1.76 \\
1.24 \\
0.35 \\
1.35 \\
0.18\end{array}$ & $\begin{array}{l}\% \\
26 \\
14 \\
27 \\
48 \\
\end{array}$ \\
\hline
\end{tabular}

* This value was calculated from the data obtained at the intersection of the free and ester curves in subjects CHC-2, $-3,-4$, and -5 . Since the curves of subject CHC-6 and $\mathrm{CHT}-1$ did not intersect, the values are calculated from the maximum observed specific activities of free and ester cholesterol.

$\dagger$ As discussed in the text, the curves of subjects $\mathrm{CHC}-6$ and CHT-1 did not intersect. The early portions of the "ester" data in subject CHC-4 were lost due to a laboratory accident.

respectively, of the labeled dietary cholesterol was found in the plasma cholesterol at the maximum specific activity of the free fraction.

Expired carbon dioxide had no measureable radioactivity; as little as 0.1 per cent of the administered dose per day. could have been detected by the method used.

\section{DISCUSSION}

\section{Absorption and excretion of labeled cholesterol}

The specific activity of plasma cholesterol would rise rapidly to an early peak, if the process of cholesterol absorption from the intestine was relatively rapid. This would be analogous to the behavior of plasma glucose after a glucose tolerance test. However, the experimental results in man show that the peak specific activity is not reached until approximately the second or third day. This suggests either that absorption is slow, that absorbed cholesterol is retained in the intestinal mucosa, or that newly absorbed cholesterol is rapidly removed from the blood and then later reintroduced into the circulation. Biggs and his co-workers (13) concluded that cholesterol absorption was slow, since they observed a sustained fecal excretion of radioactivity after feeding tritium labeled cholesterol. However, these authors measured either the total fecal radioactivity, or in one instance, the activity of a crude extract that contained cholesterol, coprosterol and possibly other steroids. Therefore, the fraction of the total radioactivity in the form of unabsorbed cholesterol and the fraction which represented cholesterol that had been absorbed, transformed into other metabolites and subsequently excreted in feces is unknown. The experiments of Siperstein, Jayko, Chaikoff, and Dauben (14) indicate that after administration of cholesterol the sustained fecal excretion of radioactivity is chiefly in the form of acidic transformation products, such as bile acids. Animal studies $(15,16)$ show that dietary cholesterol is absorbed within one day and is esterified during the absorptive process. Both the free and esterified sterol pass into the intestinal lymphatics and enter the venous side of the circulation. Although the rate of cholesterol absorption in man has not been directly determined, it seems unlikely that slow absorption is responsible for the relatively delayed appearance of the maximum specific activity.

No information is available about the possible holdup of cholesterol in the intestinal mucosa, although this would seem unlikely in view of its rapid appearance in lymph (15). With respect to the possibility that newly absorbed cholesterol is initially removed from the blood, animal experiments show that injected colloidal suspensions of cholesterol resembling chylomicrons rapidly disappear from the circulation and that the cholesterol thus removed subsequently reappears in the plasma $(17,18)$. In addition, although cholesterol esterification during the process of intestinal absorption is well documented $(15,16,19)$, there is no evidence that the esters thus formed are identical with those normally found in the circulation. The slow rise observed in the plasma free and ester specific activity curves can tentatively be ascribed to relatively rapid absorption of the sterol from the intestine, rapid removal of the newly absorbed sterol from the blood, followed by its subsequent reappearance in the circulation.

The absorption of the fed cholesterol-4-C ${ }^{14}$ varied from 52 to 86 per cent (Table VI) as determined by the amount that was excreted in the feces during the first four days. These values are higher than those reported for the absorption of one gram doses of tritium labeled cholesterol (13). With the exception of CHC-5, the subjects in this study received approximately $10 \mathrm{mg}$. of labeled 
cholesterol and the efficiency of absorption may be related to the large difference in the amount fed. It should be noted that patient, CHC-5, who received one gram of cholesterol- $d$ with the tracer dose of radioactive sterol showed the smallest absorption of cholesterol (52 per cent). The portion of the fecal radioactivity derived from cholesterol-4- $\mathrm{C}^{14}$ that had been absorbed, metabolized, and subsequently excreted, and that which had completely escaped absorption are not known. Since only 0.35 to 1.76 per cent of the cholesterol4-C ${ }^{14}$ appeared in the urine, the kidney is a minor route for the excretion of the steroid nucleus; a considerable fraction of the urinary radioactivity is in the form of steroid hormone metabolites (9).

After the feeding of cholesterol, from 4 to 15 per cent was present in the circulation at the maximum specific activity of free cholesterol (Table VI). Without considering any other tissues, the human liver contains about $4.5 \mathrm{gm}$. of cholesterol in isotope equilibrium with plasma cholesterol (18) and an additional three grams of sterol are in the red cells, which after 24 to 36 hours are also in equilibrium with plasma free cholesterol (9). Thus approximately 8 to 33 per cent of the administered dose is present in the liver and circulation, thereby accounting for a significant fraction of the sterol absorbed from the diet.

The fact that no labeled carbon dioxide was detected after the administration of cholesterol-4- $\mathrm{C}^{14}$ shows that carbon- 4 remained attached to the rest of the steroid nucleus. This suggests that the steroid nucleus is not degraded and is probably eliminated from the body in an intact form, either through the urine, feces or skin. This finding is in agreement with the results of Chaikoff and his colleagues (20) who have shown that the carbon-4 of cholesterol-4-C ${ }^{14}$ was not converted to carbon dioxide by the rat, although cholesterol labeled at $\mathrm{C}-26$ can be oxidized with the appearance of $\mathrm{C}^{14} \mathrm{O}_{2}$ in the expired air.

\section{Plasma cholesterol radioactivity curves}

In all the patients who received labeled cholesterol, except CHT-1 with xanthoma tuberosum and $\mathrm{CHC}-6$ with the nephrotic syndrome, the plasma cholesterol specific activity curves behave in the characteristic manner described. The data of Biggs and his co-workers (13) who fed tritium labeled cholesterol are essentially similar to those reported here except that the specific activity of total plasma cholesterol was measured rather than that of ester cholesterol. Since 60 to 75 per cent of plasma cholesterol is esterified, measurements of total cholesterol give a good approximation of the specific activity of the ester fraction. Warner (21) mentions that the specific activity of free cholesterol is higher than that of ester during the "period of active absorption."

The curves for plasma free and ester cholesterol derived from the diet decline at similar rates after reaching their maxima and are comparable to the behavior of plasma cholesterol synthesized in the body from acetate. The ester specific activity remains higher than that of the free because the free cholesterol is continually being diluted by non-labeled cholesterol from the diet or by endogenous synthesis. A more complete description of this process appears elsewhere (1). The behavior of the free and ester cholesterol shown in Figure 2, fits the criteria of Zilversmit, Entenman, Fishler, and Chaikoff (22) for the relationship between precursor (free) and product (ester). Inasmuch as free cholesterol was given, the free sterol must be the ultimate precursor of the plasma ester cholesterol.

The declining portion of the specific activity curves may be resolved into the component exponential rates listed in Table V. Since both distribution phenomena and biochemical reactions contribute to the processes which account for the decline in specific activity, no unique significance can be attached to these rates; however, they are useful in characterizing the curves.

The congruity of the specific activity curves derived from either $\mathrm{C}^{14}$ or tritium labeled acetate, as illustrated in Figure 1, shows that acetate labeled with either isotopes may be used for the study of cholesterol metabolism. It is also noteworthy that the plasma cholesterol of subject CHC-5 who received cholesterol-4- $\mathrm{C}^{14}$ and cholesterol-d simultaneously possessed a constant deuterium to $\mathrm{C}^{14}$ ratio at several points on the specific activity curve where measurements were made (Table III). This implies the identical 
handling of cholesterol-4-C $\mathrm{C}^{14}$ and deuterium-labeled cholesterol by the body.

If the rates describing the decline of plasma cholesterol derived from cholesterol-4-C $\mathrm{C}^{14}$ are compared with those representing the decline of plasma cholesterol formed by endogenous synthesis from acetate-2-C $\mathrm{C}^{14}$, it will be noted that they are remarkably similar. This is illustrated graphically in Figures 3 and 4 . Either labeled cholesterol or labeled acetate may be used interchangeably to trace the decay curve of plasma cholesterol, provided it is recognized that the early portions of the specific activity curves derived from these two tracer materials are different.

\section{Studies in hypercholesterolemia}

The altered relationship between free and ester cholesterol in the subject with xanthoma tuberosum (Figure 5) as compared with patients with xanthoma tendinosum or normocholesterolemic subjects has been observed previously (23). While there are no comparable studies in nephrosis, the similarity of the plasma cholesterol specific activity curves in xanthoma tuberosum with those of the nephrotic syndrome (Figure 6) should be emphasized. Since in both the xanthoma tuberosum and the nephrotic syndromes but, not in xanthoma tendinosum, the plasma appears lipemic and excessive amounts of neutral fat, phospholipids and the abnormal Sf 10-400 lipoproteins (24) are found, the higher initial specific activity of plasma ester cholesterol may perhaps be correlated with these findings which are characteristic of essential hyperlipemia in addition to hypercholesterolemia. Excessive esterification during absorption or a modified esterification process during lipoprotein synthesis by liver may be responsible for the abnormal relation between plasma free and ester cholesterol.

There are no findings in the data from the four patients with hypercholesterolemia that might aid in explaining the sustained elevation of the plasma cholesterol. The decline of the specific activity curves in these patients is not appreciably different from those of patients with normal cholesterol levels. Since the component exponential processes which form the decay curves are many in number, and have not been individually evaluated by any experimental procedure, small deviations that might be implicated in the maintenance of the elevated cholesterol levels may be "buried" in the curve. Small sustained differences in the rate of decay could bring about large cumulative changes in the plasma cholesterol level.

\section{Interrelations of dietary and biosynthetic cho- lesterol}

Dietary cholesterol and cholesterol made in vivo from acetate differ in metabolism only during the immediate post-absorptive and post-synthetic period in that biosynthetic cholesterol rapidly appears in the blood while the peak circulatory level of dietary cholesterol is delayed. However, the radioactivity data indicate conclusively that the two "species" of cholesterol merge by the third or fourth day following synthesis or ingestion. The fed, performed cholesterol is then indistinguishable from that synthesized from acetate except by application of isotope techniques. Since biosynthetic cholesterol is constantly secreted in the bile and mixes in the intestine with cholesterol present in food, a mixture of preformed and biosynthetic cholesterol is always available for absorption.

One difference between fed and biosynthesized cholesterol may be in the mode of transport immediately after either formation or absorption. It is likely that biosynthetic cholesterol is secreted into the circulation from the site of synthesis in combination with lipoprotein. The molecular form in which dietary cholesterol enters the circulation via the lymph is unknown and may differ in physical properties from lipoprotein-bound endogenous cholesterol. Since the physiological processes that give rise to both "species" are continuous, both forms are present in the circulation at the same time, and the possibility remains that the immediate post-absorptive phase of cholesterol metabolism is critical ; further studies of these implications are in progress.

\section{SUM MARY}

1. Cholesterol and acetate, labeled with either radiocarbon or radiohydrogen, have been used to trace the metabolic behavior of plasma cholesterol synthesized in vivo or derived from the diet in 
human subjects with normal and elevated plasma sterol levels.

2. From 4 to 27 per cent of a $10 \mathrm{mg}$. dose of labeled cholesterol appeared in the plasma after oral administration, 14 to 48 per cent was recovered in the feces during the first four days and approximately one per cent appeared in the urine. As suggested by the absence of measureable radioactivity in expired carbon dioxide, there was no evidence for the breakdown of the steroid nucleus.

3. Traces of orally administered cholesterol-4$\mathrm{C}^{14}$ could be detected in the plasma within one hour and the maximum radioactivity of free and ester cholesterol was attained in two to three days. This is in contrast to labeled plasma cholesterol synthesized in vivo from radioactive acetate which reaches peak specific activity within eight hours.

4. No differences in the patterns of incorporation could be detected in two patients with hypercholesterolemia accompanying the xanthoma tendinosum syndrome when compared with subjects having normal sterol levels. Differences in the relation of free to ester cholesterol were observed during the incorporation of dietary cholesterol in a patient with hypercholesterolemia accompanying the xanthoma tuberosum syndrome and in another subject with hypercholesterolemia of the nephrotic syndrome.

5. Aside from early differences in the appearance of biosynthetic and dietary cholesterol in plasma cholesterol, the data suggest that cholesterol derived from the diet is eventually indistinguishably mixed with cholesterol synthesized in the body.

\section{ACKNOWLEDGMENTS}

The authors are indebted for the devoted assistance of Vincent Abate, Mones Berman, William Considine, Hilda Denman, Albert Deutsch, Larrier Hendrickson, Joseph Knoll, Ruth Loevinger, and Barbara Weintraub.

\section{REFERENCES}

1. Hellman, L., Rosenfeld, R. S., and Gallagher, T. F., Cholesterol synthesis from $C^{14}$-acetate in man. J. Clin. Invest., 1954, 33, 142.

2. Halford, J. O., and Anderson, L. C., Organic deuterium compounds. Acetic, malonic and succinic acids. J. Am. Chem. Soc., 1936, 58, 736.

3. Belleau, B., and Gallagher, T. F., The conversion of $\Delta^{4}$-cholestene-3-one to cholesterol. J. Am. Chem. Soc., 1951, 73, 4458.
4. Bloch, K., and Rittenberg, D., The preparation of deuterio cholesterol. J. Biol. Chem., 1943, 149, 505.

5. Schenck, F., Buchholz, K., and Wiese, O., Untersuchungen am 7-Dehydro-cholesterin. Ber. d deutsch. chem. Gesellsch., 1936, 69, 2696.

6. Rosenkranz, G., Mancera, O., Gatica, J., and Djerassi, C., Steroids. IV. Alpha-iodoketones. A method for the conversion of allosteroids into $\Delta^{4}$-3-ketosteroids. J. Am. Chem. Soc., 1950, 72, 4077.

7. Rosenfeld, R. S., Hellman, L., Considine, W. J., and Gallagher, T. F., Isolation of radioactive cholesterol from plasma. J. Biol. Chem., 1954, 208, 73.

8. Hellman, L., Rosenfeld, R. S., Fukushima, D. K. Gallagher, T. F., and Dobriner, K., Utilization of $\mathrm{C}^{\mathbf{1 4}}$-acetate for cholesterol and steroid hormone synthesis in the human. J. Clin. Endocrinol., 1952, 12, 934.

9. Hellman, L., Rosenfeld, R. S., Fukushima, D. K., Eidinoff, M., and Gallagher, T. F., The major pathways of steroid metabolism in man. J. Clin. Invest., 1953, 32, 573.

10. Eidinoff, M., Internal gas counting of radioactive carbon and hydrogen. American Institute of Electrical Engineers, 2nd Annual Joint Conference on Electronics in Nucleonics and Medicine, New York: A. I. E. E., 1950, p. 65, (A. I. E. E. Special publication No. 33).

11. Glascock, R. F., A combustion technique for the assay of tritium, ${ }^{13} \mathrm{C}$, and ${ }^{14} \mathrm{C}$ in a single $10 \mathrm{mg}$. sample of biological material. Biochem. J., 1952, 52, 699.

12. Eidinoff, M. L., Measurement of radiocarbon as carbon dioxide inside Geiger-Müller counters. Analyt. Chem., 1950, 22, 529.

13. Biggs, M. W., Kritchevsky, D., Colman, D., Gofman, J. W., Jones, H. B., Lindgren, F. T., Hyde, G., and Lyon, T. P., Observations on the fate of ingested cholesterol in man. Circulation, 1952, 6, 359.

14. Siperstein, M. D., Jayko, M. E., Chaikoff, I. L., and Dauben, W. G., Nature of the metabolic products of $\mathrm{C}^{\mathbf{1 4}}$-cholesterol excreted in bile and feces. Proc. Soc. Exper. Biol. \& Med., 1952, 81, 720.

15. Bollman, J. L., and Flock, E. V., Cholesterol in intestinal and hepatic lymph in the rat. Am. J. Physiol., 1951, 164, 480.

16. Friedman, M., Byers, S. O., and Shibata, E., Observations concerning the production and excretion of cholesterol in mammals. X. Factors affecting the absorption and fate of ingested cholesterol. J. Exper. Med., 1953, 98, 107.

17. Bevans, M., Abell, L. L., and Kendall, F. C., Production of intimal atherosclerosis by intravenous injection of colloidal cholesterol into rabbits. Federation Proc., 1948, 7, 269.

18. Unpublished results from this laboratory. 
19. Chaikoff, I. L., Bloom, B., Siperstein, M. D., Kiyasu, J. Y., Reinhardt, W. O., Dauben, W. G., and Eastham, J. F., Cld-cholesterol. I. Lymphatic transport of absorbed cholesterol-4-C ${ }^{14}$. J. Biol. Chem., 1952, 194, 407.

20. Chaikoff, I. L., Siperstein, M. D., Dauben, W. G., Bradlow, H. L., Eastham, J. F., Tomkins, G. M., Meier, J. R., Chen, R. W., Hotta, S., and Srere,

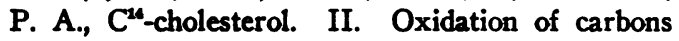
4 and 26 to carbon dioxide by the intact rat. J. Biol. Chem., 1952, 194, 413.

21. Warner, I., Rate of appearance of dietary cholesterol in blood. Federation Proc., 1952, 11, 306.
22. Zilversmit, D. B., Entenman, $C_{\text {, }}$ Fishler; M. C., and Chaikoff, I. L., The turnover rate of phospholipids in the plasma of the dog as measured with radioactive phosphorus. J. Gen. Physiol., 1943, 26, 333.

23. Biggs, M. W., and Colman, D., A quantitative metabolic defect in lipid metabolism associated with abnormal serum lipoproteins in man. Circulation, 1953, 7, 393.

24. Gofman, J. W., Jones, H. B., Lindgren, F. T., Lyon, T. P., Elliott, H. A., and Strisower, B., Blood lipids and human atherosclerosis. Circulation, 1950, 2, 161. 